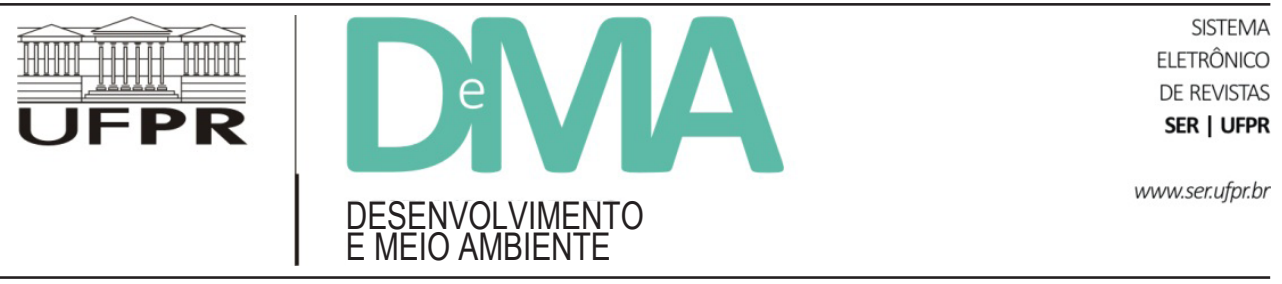

\title{
Conservação de remanescentes florestais no Brasil: considerações sobre os principais instrumentos de gestão ambiental
}

\section{Conservation of Forest Remnants in Brazil: Considerations on the Main Instruments for Environmental Management}

\author{
Flora Bonazzi PIASENTIN ${ }^{1 *}$, Susana Lena Lins de GÓIS ${ }^{2}$ \\ ${ }^{1}$ Centro de Ciências Agrárias, Ambientais e Biológicas, Universidade Federal do Recôncavo da Bahia (UFRB), Cruz das Almas, BA, Brasil. \\ ${ }^{2}$ Departamento de Transferência de Tecnologia (DTT), Empresa Brasileira de Pesquisa Agropecuária (Embrapa), Brasília, DF, Brasil. \\ *E-mail de contato: florapro2002@yahoo.com.br
}

Artigo recebido em 10 de agosto de 2015, versão final aceita em 16 de março de 2016.

RESUMO: A perda de biodiversidade é um problema que atinge diversos ecossistemas naturais no mundo, ocorrendo com taxas alarmantes e crescentes. A redução dessas taxas consiste no principal compromisso assumido entre os países que compõem a Convenção sobre Diversidade Biológica. Este artigo se propõe a examinar alguns dos instrumentos de gestão ambiental (de regulação direta ou comando e controle e econômicos) existentes no Brasil para alcançar este compromisso, em especial com referência à conservação de remanescentes florestais. Para tanto, apresentam-se os principais instrumentos de comando e controle adotados e instituídos por meio do Código Florestal Brasileiro (1934; 1965; 2012a) e do Sistema Nacional de Unidades de Conservação (2000), entre outros dispositivos regulatórios. São considerados também alguns instrumentos econômicos, como o Imposto sobre Circulação de Mercadorias e Prestação de Serviços (ICMS) Ecológico e os incentivos associados à criação de Reservas Particulares do Patrimônio Natural (RPPNs). Analisa-se o conjunto destes instrumentos sob a luz de sua eficácia para a manutenção da cobertura florestal em áreas públicas e privadas. Discutem-se as limitações e potencialidades das normas governamentais, observando-se a predominância de instrumentos de comando e controle em relação aos instrumentos econômicos. Por fim, conclui-se que é necessário o aprimoramento da estratégia governamental relativa à conservação de remanescentes por meio de ações de fortalecimento do desempenho dos instrumentos regulatórios disponíveis e sua complementação por novos instrumentos econômicos.

Palavras-chave: instrumentos de comando e controle; instrumentos econômicos; legislação ambiental brasileira: conservação florestal. 
ABSTRACT: Biodiversity loss is a problem that affects several natural ecosystems in the world, occurring in alarming and crescent rates. The reduction of these rates consists in the main commitment agreed among countries that participate in the Biological Diversity Convention. This article aims at examining some of the existing legal and economic instruments in Brazil to achieve this commitment, specially regarding the conservation of forest remnants. The main command and control instruments employed and established through the Brazilian Forest Code $(1934 ; 1965 ; 2012 a)$ and the National System of Conservation Areas (2000), among other regulatory devices, are presented. Some economic instruments also considered are the Ecological Goods and Services Tax and the Private Reserve of Natural Heritage. These instruments are analyzed in light of their efficacy in maintaining the forest cover in public and private areas. Their limitations and potentialities are discussed while the predominance of command and control instruments over the economic ones is observed. Finally, it is concluded that the needed improvement of the governmental strategy towards the conservation of forest remnants could be achieved by strengthening the performance of the available command and control instruments, complementing those with new economic instruments.

Keywords: command and control instruments; economic instruments; Brazilian environmental legislation; forest conservation.

\section{Introdução}

Os ativos ambientais presentes nos ecossistemas estão na base das condições que permitem a vida humana no planeta. A perda de biodiversidade altera os ecossistemas, compromete sua capacidade de fornecer bens e serviços ambientais e causa, dessa forma, uma deterioração na qualidade de vida dos seres humanos (Secretariado da Convenção sobre Diversidade Biológica, 2006). O Secretariado da Convenção sobre Diversidade Biológica (2006) alertou para a tendência crescente das taxas de perda de biodiversidade em nível global, onde a conversão de florestas para outros usos destaca-se como principal elemento.

A destruição de florestas tropicais representa um enorme passivo ambiental para a humanidade, visto que estas áreas detêm o maior repositório de diversidade biológica no mundo (Ayres et al., 2005). No Brasil, país que sozinho abriga $1 / 3$ das florestas tropicais do mundo, o grau de conversão de ecossistemas florestais para outros usos é considerado preocupante (Ayres et al., 2005; Irigaray, 2007). Só na Amazônia a taxa de desmatamento é de dois milhões de hectares ao ano (Irigaray, 2007) e alguns biomas brasileiros, como a Mata Atlântica e o Cerrado, encontram-se sob forte ameaça de extinção e restritos a uma pequena porção de sua extensão original na forma de remanescentes (Ayres et al., 2005). É nesse contexto que os esforços para a conservação de remanescentes ou fragmentos florestais no Brasil assumem importância estratégica para a redução da erosão de biodiversidade global (Soulé, 1991). De acordo com Viana (1990), fragmentos florestais são áreas de vegetação natural interrompidas por barreiras antrópicas ou naturais, capazes de diminuir significativamente o fluxo de animais, pólen e sementes.

A conservação de remanescentes florestais contribui para a integridade ecológica dos biomas, aumentando a conectividade dos corredores ecológicos e reduzindo a fragmentação da paisagem (Brito, 2006). A paisagem resulta da interação dinâmica e contínua entre processos naturais e a atividade humana (Antrop, 2006) e é sustentável, na medida em que permite a manutenção da provisão de bens e serviços ambientais (Potschin \& Haines-Young, 2006). 
Ações em prol da conservação adquiriram maior força após 2002, quando os países membros da Convenção sobre Diversidade Biológica (ONU, 1992), da qual o Brasil faz parte, se comprometeram a alcançar até 2010 uma redução significativa das taxas de perda de biodiversidade (MMA, 2007). O Brasil traduziu este objetivo em metas nacionais de biodiversidade para 2010, que passaram a entrar em vigor com a Resolução 3/2006 da Comissão Nacional de Biodiversidade (CONABIO) (MMA, 2007). Dentre as metas relevantes para a efetiva promoção da conservação de remanescentes dos biomas brasileiros, estiveram a conservação de pelo menos $30 \%$ do Bioma Amazônia e 10\% dos demais biomas e da Zona Costeira e Marinha e a redução na taxa de desmatamento de $100 \%$ no bioma Mata Atlântica, de $75 \%$ no bioma Amazônia e de 50\% nos demais biomas (MMA, 2007). No período 2011-2020, o país reforçou as metas nacionais de conservação previamente assumidas para o bioma da Amazônia e para as áreas marinhas e costeiras e aumentou a meta dos demais biomas para 17\% (CONABIO, 2013).

Para a efetivação dessas metas, o Brasil conta com um marco legal composto por políticas na forma de leis, resoluções, etc., que se operacionalizam por meio de instrumentos de gestão ambiental. Dois são os instrumentos de gestão ambiental comumente utilizados e regulados pelo Estado. Os primeiros, de regulação direta, do tipo comando e controle (C\&C), também conhecidos como instrumentos regulatórios, são os principais instrumentos aplicados no Brasil. Esses correspondem ao sistema onde o poder público estabelece os padrões e monitora a qualidade ambiental, regulando as atividades e aplicando sanções e penalidades, via legislação e normas (Leal, 1997). Os segundos, denominados de instrumentos de incentivo ao mercado ou instrumentos econômicos (IEs), têm a finalidade de reduzir a regulamentação estatal, com vistas a propiciar uma maior flexibilidade aos agentes de mercado, reduzir os custos de controle dos problemas ambientais e estimular o desenvolvimento de tecnologias mais limpas.

Este artigo aborda a estratégia governamental brasileira para a conservação de remanescentes florestais com foco nos principais instrumentos de gestão ambiental adotados. Primeiramente, faz-se uma breve descrição das principais políticas e dos instrumentos empregados. Posteriormente, destacam-se as limitações e oportunidades destes instrumentos frente ao efetivo alcance das metas de biodiversidade. Por fim, faz-se uma reflexão sobre o desempenho da estratégia, delineando-se recomendações para o seu aprimoramento.

\section{Principais políticas de conservação de remanescentes florestais}

\subsection{Legislação ambiental br,asileira - os instrumentos legais de regulação direta}

Existe um amplo conjunto de medidas legislativas que assegura a proteção de florestas e remanescentes florestais no Brasil. Destas, cabe destacar o Código Florestal (Brasil, 1934; 1965; 2012a), a Política Nacional de Meio Ambiente (1981), a Lei de Crimes Ambientais (Brasil, 1998a), o Sistema Nacional de Unidades de Conservação (SNUC) (Brasil, 2000) e algumas regulamentações dadas pelas Resoluções do Conselho Nacional de Meio Ambiente (CONAMA).

$\mathrm{O}$ primeiro marco regulador que definiu as florestas como bens de interesse comum, impondo restrições ao uso e ocupação de áreas florestadas foi estabelecido com o Código Florestal (Decreto 23.793/34) (Fonseca, 2012). Este instituiu que os proprietários deveriam manter um quarto $(25 \%)$ de 
seus imóveis rurais com a cobertura de mata original e que deveriam preservar as florestas denominadas protetoras por exercerem um importante papel para o controle de erosão em áreas de risco e para a proteção de recursos hídricos (Fonseca, 2012). No Código Florestal sucessivo, criado pela Lei 4.771/65, esses dois requisitos deram origem a dois instrumentos para a conservação ambiental no âmbito da propriedade rural: a Reserva Legal (RL) e as Áreas de Preservação Permanente (APP). As APPs e as RLs consubstanciavam uma tentativa de conter os avanços sobre a floresta. A primeira, declarando intocáveis todos os espaços cuja presença da vegetação garante sua integridade, e a segunda, transferindo compulsoriamente para os proprietários rurais a responsabilidade e o ônus da proteção (Medeiros, 2006). Com a aprovação do novo Código Florestal em 2012 (Brasil, 2012a), houve mudanças que diminuíram as restrições de uso nas áreas de APPs e RLs, especificamente para a pequena propriedade ou posse rural familiar. Além disso, foram criadas as Áreas de Uso Restrito, que incluem pantanais, planícies pantaneiras e áreas de inclinação entre $25^{\circ}$ e $45^{\circ}$, nas quais a exploração deve ocorrer de forma sustentável e a supressão de novas áreas depende de autorização do órgão ambiental.

Já a Lei 6.938 (Brasil, 1981), que institui a Política Nacional do Meio Ambiente (PNMA), define os diversos instrumentos legais de gestão ambiental, dos quais destacam-se: o licenciamento de atividades efetiva ou potencialmente poluidoras; a criação de espaços territoriais especialmente protegidos; as penalidades disciplinares ou compensatórias ao não cumprimento das medidas necessárias à preservação ou correção da degradação ambiental; e instrumentos econômicos. Esses instrumentos assumem relevância direta para a promoção da manutenção de remanescentes florestais.
Como se observa, a regulação estatal tem sido um dos principais instrumentos de intervenção no estabelecimento de regras que demarcam as possibilidades de uso e ocupação do território, a promoção da proteção ambiental e a emergência de arranjos institucionais entre Estados, Municípios e a sociedade civil com o objetivo de garantir uma maior sustentabilidade às ações governamentais.

A Constituição Federal (Brasil, 1998b) não somente dedica um capítulo específico sobre o meio ambiente (artigo 225), como também expressa a componente ambiental da função social da propriedade rural em seu artigo 186, quando exige, para seu cumprimento, a utilização adequada dos recursos naturais e a preservação do meio ambiente. Ela fundamenta e reforça, portanto, as limitações legais ao uso dos recursos florestais na propriedade privada previstas no Código Florestal e tem, em legislações específicas, a criação de espaços territoriais a serem especialmente protegidos ${ }^{1}$.

Nesse artigo serão analisadas, no âmbito dos instrumentos de comando e controle, as APPs, RLs e Unidades de Conservação (UCs), que representam as principais categorias de áreas oficialmente protegidas com potencial para a conservação da biodiversidade em remanescentes florestais no país (CONABIO, 2013). Além disso, irão ser apresentadas as penalidades disciplinares e um sistema de licenciamento ambiental voltado às propriedades rurais como instrumentos eficazes para a implementação de alguns desses espaços.

\subsection{1. Área de Preservação Permanente-APP}

As Áreas de Preservação Permanente são áreas protegidas por Lei Federal, "área protegida, 
coberta ou não por vegetação nativa, com a função ambiental de preservar os recursos hídricos, a paisagem, a estabilidade geológica e a biodiversidade, facilitar o fluxo gênico de fauna e flora, proteger o solo e assegurar o bem-estar das populações humanas" (Lei 12.651/2012, art. $3^{\circ}$, inciso II). Dada sua característica de restrições de uso, estas áreas visam garantir a integridade dos remanescentes florestais e, por conseguinte, a manutenção de serviços ambientais.

O Código Florestal especifica as categorias de áreas a serem protegidas, as quais não podem ser suprimidas. A intervenção ou a supressão da vegetação nessas áreas apenas é admitida mediante prévia autorização do poder executivo federal para atender o interesse social, em caso de necessidade pública ou para execução de atividades de baixo impacto ambiental (Lei 12.651/2012, art. $8^{\circ}$ ). Com a aprovação da Lei 12.651/2012, apenas na pequena propriedade ou posse rural familiar passou-se a admitir nas APPs o plantio de espécies exóticas (até o limite de 50\%) em consórcio com espécies nativas e outras atividades de baixo impacto ambiental. Ademais, houve uma redução da faixa obrigatória que deve ser mantida ao longo dos rios. Dessa forma, houve um decréscimo do potencial dessa categoria de espaço protegido para a conservação da biodiversidade com a nova Lei.

\subsubsection{Reserva Legal - RL}

\section{A RL trata da}

área localizada no interior de uma propriedade rural [...] com a função de assegurar o uso econômico de modo sustentável dos recursos naturais do imóvel rural, auxiliar a conservação e a reabilitação dos processos ecológicos e promover a conservação da biodiversidade, bem como o abrigo e a proteção de fauna silvestre e da flora nativa (Brasil, 2012a, Lei 12.651/2012).

Ou seja, as florestas e outras formas de vegetação nativa podem ser suprimidas desde que mantido, a título de RL, um percentual da propriedade necessário ao cumprimento de sua finalidade. Estes percentuais, também definidos por Lei (Lei $12.651 / 2012)^{2}$, correspondem a uma parcela da propriedade rural que não pode ser suprimida, mas apenas utilizada sob regime de manejo florestal sustentável, ou seja, dentro de limites que assegurem a reprodução e a manutenção da vegetação original.

Embora inexistam dados oficiais que indiquem o número e a extensão total das áreas de RL no país (Medeiros \& Garay, 2006), a conservação de remanescentes florestais, por estar presente em todos os imóveis rurais, estaria assegurada por esta tipologia de área protegida, caso houvesse cumprimento das normas legais (Medeiros \& Garay, 2006).

A legislação que trata desta temática é maleável em alguns aspectos e fornece alguns incentivos e flexibilidade à preservação ou à conservação que vão além da obrigação legal. Dentre os elementos que dão flexibilidade, destacam-se quatro componentes. O primeiro permite que as APPs sejam computadas no cálculo do percentual de RL; o segundo ponto conclui que a RL possa ser instituída em regime de condomínio entre mais de uma propriedade; o terceiro aspecto prevê o apoio técnico do órgão ambiental à pequena propriedade ou posse rural familiar no processo de recomposição da RL de sua propriedade; e, finalmente, permite

\footnotetext{
$280 \%$ na propriedade rural situada em área de floresta localizada na Amazônia Legal; 35\% em área de cerrado na Amazônia Legal; e 20\% em área de floresta ou outras formas de vegetação nativa localizada nas demais regiões do País ou em área de campos gerais localizada em qualquer região do País.
} 
que nestas mesmas propriedades sejam computados os plantios de árvores frutíferas ornamentais ou industriais, compostos por espécies exóticas (até o limite de $50 \%$ da área), cultivadas em sistema intercalar ou em consórcio com espécies nativas - fato que confere à pequena propriedade a alternativa de manejo com utilização de espécies de rentabilidade econômica (Brasil, 2012a; Fonseca, 2012; Wollmann \& Bastos, 2015). Por fim, com o novo Código Florestal (Lei 12.651/2012), houve uma flexibilização dos percentuais da área de RL: a pequena propriedade ou posse rural familiar (imóveis de até quatro módulos fiscais) que possua remanescente de vegetação nativa em percentuais inferiores ao previsto no bioma onde se encontra pode constituir a RL com a área ocupada com a vegetação nativa existente até 22 de julho de 2008 (área rural consolidada), não necessitando recompô-la (Wollmann \& Bastos, 2015). Esse limite temporal se deve à publicação do decreto 6.514 (Brasil, 2008), que regulamenta a Lei de Crimes Ambientais (Lei n. 9.605) (Brasil, 1998a), fixando prazo de 180 dias para que todos os proprietários de imóveis rurais averbassem nos cartórios suas áreas de Reserva Legal (Fonseca, 2012).

No que se refere aos incentivos, ressalta-se a desoneração, por parte do proprietário rural, das obrigações previstas para recompor a reserva legal, conduzir sua regeneração natural ou de sua compensação, mediante a doação ao órgão ambiental de área localizada no interior de unidade de conservação de domínio público, pendente de regularização fundiária. Outro elemento importante é a instituição da servidão ambiental como instrumento econômico previsto na PNMA, em que o proprietário rural é remunerado pela renúncia voluntária dos direitos de supressão ou exploração da vegetação nativa, localizada fora da RL e da APP. Com o regime de servidão ambiental, o proprietário ou possuidor do imóvel rural adquire a Cota de Reserva Ambiental título representativo de área com vegetação nativa, existente ou em processo de recuperação.

\subsubsection{Unidades de Conservação - UCs}

A principal estratégia de conservação da biodiversidade no mundo, bem como no Brasil, tem sido a criação de áreas protegidas (Naughton-Treves et al., 2005). No Brasil, esta estratégia foi institucionalizada por meio da Lei 9.985 (Brasil, 2000), que instituiu o Sistema Nacional de Unidades de Conservação Naturais (SNUC).

As Unidades de Conservação (UCs), criadas por ato do poder público, comportam os espaços territoriais e seus recursos ambientais, com características naturais relevantes, com objetivos de conservação e limites definidos, sob regime especial de administração, aos quais se aplicam garantias adequadas de proteção.

As Unidades de Proteção Integral (UCPI) e as de Uso Sustentável (UCUS) são os grupos que integram o Sistema Nacional de Unidades de Conservação (SNUC). As primeiras objetivam a preservação da natureza, sendo admitido apenas o uso indireto dos seus recursos naturais; as segundas visam à compatibilização entre conservação da natureza e o uso sustentável de parcela dos seus recursos naturais.

As UCs são, pois, uma ferramenta importante para a preservação e a conservação dos recursos ambientais, na medida em que se sustentam em atividades que favorecem o desenvolvimento socioeconômico, a manutenção da qualidade do meio ambiente e do equilíbrio ecológico.

Apesar do número considerável de UCs implantadas no país, este ainda é bem inferior ao percentual de $10 \%$ de cada bioma, meta estabele- 
cida pela CDB (Tabarelli et al., 2005; Brito, 2006). Apenas um percentual inferior a $6 \%$ do bioma Mata Atlântica, por exemplo, encontrava-se protegido em 2007 (Freitas, 2007). Ademais, muitas UCPI sofrem contínuas invasões e degradação devido às dificuldades de fiscalização dos órgãos e entidades governamentais responsáveis, que contam com limitados recursos financeiros, logísticos e humanos (Tabarelli et al., 2005).

Outra debilidade desta estratégia advém de sua operação dentro do paradigma das "ilhas biológicas", que tem um potencial limitado para a conservação da biodiversidade (Ayres et al., 2005). Isto porque o tamanho das UCs é insuficiente para manter a viabilidade de populações de espécies animais e processos ecológicos de larga escala a longo prazo (Tabarelli et al., 2005; Brito, 2006). Nesse sentido, o paradigma dos "corredores ecológicos", que visa ampliar a área das UCs por meio da conservação de remanescentes em zonas tampão para a implementação de corredores ecológicos, é considerado mais apropriado para a manutenção da integridade do ecossistema (Brito, 2006).

\subsubsection{Penalidades pelo não cumprimento} das medidas necessárias à preservação dos remanescentes em APPS, UCs e outros

As penalidades disciplinares são instrumentos da PNMA de fundamental importância para a preservação de remanescentes em áreas protegidas. Este instrumento é disciplinado pela Lei dos Crimes Ambientais (Lei 9.605) (Brasil, 1998a). Com a aprovação desta Lei, as penalidades para o dano ambiental em áreas protegidas (APPs e UCs) foram agravadas a fim de garantir uma maior eficácia da Lei na repressão à infração (Sarney Filho, 2000). Esta medida seguiu o princípio que estabelece que uma sanção, para ser efetiva, deve impor custos que excedam os benefícios econômicos gerados pela infração (Bowers, 1999). Esta Lei configura a supressão de vegetação nativa em área de APPs, UCs ou florestas de domínio público como crime contra a flora e, portanto, sujeita o infrator a multa ou/e detenção.

Com a Lei 11.428/2006 (Brasil, 2006), que trata da utilização e proteção da vegetação nativa do Bioma Mata Atlântica, a proibição de supressão da cobertura florestal (vegetação primária e secundária nos estágios avançado e médio) passou a abranger áreas que abrigam espécies ameaçadas de extinção, protejam mananciais ou previnam erosão, formem corredores ecológicos entre remanescentes, no entorno de UCs e quando possuam valor paisagístico elevado reconhecido, não estando restritas a áreas de APPs e UCs.

\subsubsection{Licenciamento de atividades efetiva} ou potencialmente poluidoras e capazes de causar degradação ambiental - o Sistema de Licenciamento Ambiental de Propriedades Rurais

Um mecanismo que vem sendo adotado, por exemplo, no Estado de Mato Grosso com bons resultados para a conservação das RLs e APPs é o Sistema de Licenciamento Ambiental de Propriedades Rurais (SLAPR) (ISA \& ICV, 2006). O SLAPR é inovador na medida em que combina diversos instrumentos de controle ambiental, como a fiscalização, o licenciamento, o monitoramento e a responsabilização, com o uso de tecnologia de geoprocessamento (ISA \& ICV, 2006). Este objetiva garantir a manutenção das áreas de RL e de APP das propriedades rurais e a coibição de seu desmatamento (ANA et al., 2004; ISA \& ICV, 
2006). Ele parte do princípio legal de que a atividade agropecuária é potencialmente degradadora do meio ambiente e, portanto, deve estar condicionada à obtenção de licença como qualquer outra atividade econômica (ISA \& ICV, 2006).

\subsection{Instrumentos Econômicos - o exemplo do ICMS-Ecológico e da Reserva Particular do Patrimônio Natural (RPPN)}

Os instrumentos de C\&C, embora sejam os mais aplicados, não dão ao agente produtor da externalidade a liberdade de promover os ajustes no tempo adequados às suas atividades produtivas e não considera as distintas situações destes agentes no cumprimento da obrigação legal (Almeida, 1997). Nesta perspectiva, os IEs têm sido apontados como uma alternativa economicamente eficiente e ambientalmente eficaz para complementar as estritas abordagens C\&C (Milaré, 2001). A aplicação dos IEs como política de gestão ambiental cumpre dois papéis: financiamento contra a poluição/degradação e incentivo que conduz o poluidor a modificar seu comportamento (Pereira \& Tavares, 1999). São eles que permeiam a PNMA, que traz em seus objetivos a imposição, ao poluidor, da obrigação de recuperar e/ou indenizar os danos causados; e, ao usuário, da contribuição pela utilização de recursos ambientais com fins econômicos. A Política Nacional de Recursos Hídricos (Brasil, 1997) é um passo importante nesta direção, na medida em que prevê, como um de seus instrumentos, a cobrança pelo uso da água (Bursztyn \& Bursztyn, 2006).

Em tese, ao fornecerem incentivos ao controle da poluição ou de outros danos ambientais, os IEs permitem que o custo social de controle ambiental seja menor e fornecem aos cofres do governo local uma fonte de receita. No entanto, os custos administrativos associados aos IEs podem ser mais elevados, em razão das exigências de monitoramento e fiscalização (Motta et al., 1996). Além disso, deve-se considerar na opção pelos IEs a necessidade de um contexto institucional consolidado, como ressaltado por Almeida (1997), pois, na presença de instituições "fracas", o potencial dos IEs seria prejudicado.

Em seguida, veremos alguns IEs adotados no Brasil e os incentivos que podem gerar a conservação de fragmentos florestais.

\subsubsection{ICMS-Ecológico}

O Imposto sobre Circulação de Mercadorias e Prestação de Serviços (ICMS) Ecológico é um destes mecanismos, visto que incorpora a dimensão ambiental dentro dos critérios de distribuição dos recursos estaduais arrecadados pela tributação que incide sobre a circulação de mercadorias e serviços (Loureiro, 1997).

Esse mecanismo também se configura como um instrumento de descentralização tributária que propicia aos estados os meios de alocação de recursos em programas de desenvolvimento ambiental municipal. O imposto proporciona a reciclagem dos recursos existentes, introduzindo um novo conceito no retorno dos valores arrecadados, instalando um critério ambiental na sua distribuição (Loureiro, 1997).

Este instrumento possibilita aos municípios o estímulo à adoção de iniciativas de conservação ambiental, seja pela criação de UCs ou pelo incentivo à incorporação de propostas que promovam o equilíbrio ecológico, a equidade social e o desenvolvimento econômico (Lins, 2005).

Vários são os Estados que já adotam critérios ambientais para a distribuição de uma parcela dos recursos gerados pelo ICMS: Paraná, São Paulo, 
Rio Grande do Sul, Mato Grosso, Mato Grosso do Sul, Pernambuco, Rondônia, Acre, Amapá, Tocantins e Minas Gerais (Bursztyn \& Bursztyn, 2006).

\subsubsection{Reserva Particular do Patrimônio Natural (RPPN)}

A opção de criar uma Reserva Particular do Patrimônio Natural (RPPN) por parte do proprietário rural é outro passo que segue os incentivos decorrentes da implementação dos IEs. Esta é uma categoria de área protegida prevista no SNUC como UCUS de domínio privado. As RPPNs são gravadas com perpetuidade e objetivam a conservação da diversidade biológica.

Ainda que restrito ao desenvolvimento de pesquisas científicas e visitação com objetivos turísticos, recreativos e educacionais, o estabelecimento de uma RPPN apresenta inúmeras vantagens econômicas ao proprietário privado, dentre as quais se destacam: a) a exclusão da área tributável do imóvel para fins de cálculo do Imposto sobre a Propriedade Territorial Rural (ITR); b) a análise prioritária de projetos referentes à implantação e gestão de RPPN para concessão de recursos oriundos do Fundo Nacional do Meio Ambiente (FNMA) e de outros programas oficiais; c) prioridade nos programas de crédito rural regulados pela administração federal; d) recebimento, pelos órgãos integrantes do SNUC, de orientação técnica e científica ao proprietário para a elaboração de um Plano de Manejo ou de Proteção e de Gestão da unidade; e, finalmente, e) poderá receber recursos de compensação ambiental no caso de um empreendimento com significativo impacto ambiental afetar diretamente a RPPN já criada (ICMBio, 2012) e receber recursos municipais para a proteção da integridade da UC (Loureiro, 2008).
Nos últimos anos, foram criadas RPPNs em vários estados brasileiros, alcançando em um curto período de existência uma ampla distribuição no território nacional. Atualmente já são mais de 1.203 RPPNs (SOS Mata Atlântica, 2016).

\subsubsection{Incentivos a sistemas agrícolas conservacionistas}

Outro importante meio para a promoção da conservação de remanescentes em propriedades rurais consiste no estímulo a práticas agrícolas de baixo impacto ambiental que sustentam agroecossistemas ambientalmente sustentáveis. A adoção dessas práticas, que seguem princípios agroecológicos e fazem um uso mais eficiente dos recursos naturais, consiste em uma das principais abordagens recomendadas para a redução da perda de biodiversidade (Soulé, 1991; Secretariado da Convenção sobre Diversidade Biológica, 2006).

Contudo, a persistência de remanescentes está estreitamente associado à manutenção de conhecimentos e práticas de uso da terra vinculadas a sistemas agrícolas tradicionais (Bowers, 1999; Austad, 2000 apud Antrop, 2006). Com efeito, estes sistemas não só mantêm importantes serviços ambientais, como a conservação da biodiversidade e o controle de erosão do solo, mas também fornecem meios de vida para populações rurais (Harrop, 2007).

Nesta perspectiva, cita-se como exemplo o sistema agroflorestal tradicional presente no sul do Estado da Bahia. Denominado de cacau-cabruca, em que o cacau é cultivado sob a sombra de árvores nativas da Mata Atlântica, é reconhecido por sua função para a conservação da biodiversidade, do solo e do clima (Sambuichi, 2002). Segundo este autor, muitas espécies arbóreas nativas, especialmente aquelas nobres, que nas áreas de floresta 
foram praticamente extintas, encontram-se comumente nessas áreas.

Apesar de sua importância para a manutenção de remanescentes e paisagens sustentáveis, o apoio governamental à manutenção e à disseminação de práticas e sistemas agrícolas ambientalmente sustentáveis tem sido limitado no país. Alguns avanços nesse sentido têm sido representados pela nova Política Nacional de Assistência Técnica e Extensão Rural para a Agricultura Familiar e Reforma Agrária (Lei 12.188/2010), fundamentada na agroecologia, e pelo Programa Nacional de Fortalecimento da Agricultura Familiar (PRONAF Agroecologia) (MDA, 2015).

Outros incentivos econômicos para a adoção de uma agricultura sustentável também provêm do mercado. Notadamente, se reconhece a certificação orgânica, que paga um prêmio ao produtor, requer o cumprimento da legislação florestal e proíbe o uso de produtos químicos e do fogo (IBD, 2012). Também se destaca o potencial de exploração da propriedade para o ecoturismo e o pagamento por serviços ambientais, tais quais a proteção de cursos de água e a conservação da biodiversidade (TNC, 1999). No âmbito do pagamento pela contribuição à provisão de serviços ambientais pela conservação de áreas de remanescentes, destaca-se a experiência do Bolsa Floresta, adotado pelo Estado do Amazonas. Ademais, os mercados de carbono também estão no bojo da oportunidade para a conservação de remanescentes, via implementação de projetos de mecanismos de desenvolvimento limpo (Young, 2005).

\section{Principais limitações e oportunidades na implementação dos instrumentos legais}

Apesar da ênfase dada à criação de UCs como instrumento legal que apresenta potencial para promover a manutenção da cobertura florestal, a maior parte dos remanescentes florestais no território brasileiro não se encontra sob regime de proteção legal, estando muitos destes situados em áreas privadas (Tabarelli et al., 2005; Amaral et $a l .$, s.d.). Considerando que estes remanescentes contribuem consideravelmente para o aumento da conectividade dentro de corredores ecológicos (Amaral et al., s.d.), é relevante avaliar a aplicação da legislação florestal, que prevê a manutenção das áreas de RL e APP em imóveis rurais.

\subsection{A implementação de RL e APP}

Embora o Código Florestal Brasileiro, que dispõe sobre a proteção da vegetação nativa, discipline a ocupação do solo em propriedades rurais com a manutenção de RL, APP e Área de Uso Restrito, a destinação dessas áreas vem sendo alterada por uma parte significativa de proprietários rurais (Sambuichi, 2002; Irigaray, 2007), os quais deveriam arcar com a obrigação legal de manter a vegetação situada nessas áreas. Irigaray (2007) identifica esta situação em relação à RL na Amazônia, enquanto Sambuichi (2002) observa o mesmo na Mata Atlântica do Sul da Bahia.

No entorno da bacia do rio São Francisco, por exemplo, que contempla os biomas Cerrado, Mata Atlântica e Caatinga, calcula-se que 60 mil hectares de APP tenham que ser recuperados por meio de reflorestamento (Menezes, 2007). Situação similar ocorre para as APPs no bioma Caatinga, conforme exemplo descrito a seguir.

Embora a utilização das APPs seja, a priori, proibida por Lei, excetuando a pequena propriedade, onde consórcios entre espécies exóticas e nativas são permitidos, estas áreas têm sido importante espaço de ocupação para atividades 
como agricultura familiar, projetos de irrigação e empreendimentos turísticos. Será analisado aqui o caso de ocupação de uma APP localizada no entorno do lago da Barragem de Sobradinho, no Estado da Bahia, por parte de agricultores familiares. Essa APP localiza-se entre os paralelos $9^{\circ}$ a $11^{\circ}$ de latitude Sul e entre os meridianos $43^{\circ}$ a $40^{\circ}$ de longitude Oeste. (MMA, 2010).

O reservatório teve sua construção iniciada em junho de 1973 e ensejou a inundação de áreas rurais e urbanas dos municípios de Casa Nova, Remanso, Santo Sé e Pilão Arcado, além de áreas rurais dos municípios de Juazeiro e Xique-Xique. Das 11.853 famílias então residentes nestes municípios, 5.806 permaneceram em lotes rurais situados no entorno do lago de Sobradinho e 3.851 famílias se estabeleceram nas novas sedes municipais (FUPEF, 2007).

A construção desta barragem não só ocupou extensas áreas de formações naturais diversificadas, como também expôs as áreas do entorno do lago à pressão antrópica. Assim sendo, as alterações ambientais decorrentes destes usos impõem a necessidade de estabelecimento de áreas de preservação dos recursos naturais, notadamente as áreas situadas no entorno do reservatório, visando garantir, inclusive, a sua vida útil (FUPEF, 2007).

A recomposição das matas ciliares nas APPs é uma das principais ações ambientais necessárias à proteção de nascentes e margens de rios ou reservatórios, tendo em vista seu relevante papel no estabelecimento do equilíbrio na relação água, solo e planta, conforme art. $2^{\circ}$, inciso II da resolução CONAMA 302/02. Na perspectiva de atender a estes requisitos, a referida Resolução define os limites das APPs de reservatórios artificiais, diferenciados em função do uso (abastecimento público, geração de energia elétrica), localização (urbana, urbana consolidada ou rural), bem como o regime de uso do seu entorno.

AAPP do entorno do lago formado pela construção da barragem de Sobradinho é definida por Lei como área de largura mínima de 100 metros, em projeção horizontal ${ }^{3}$. Neste sentido, sua delimitação foi definida por meio de sensoriamento remoto (software ArcGis), que inseriu o valor de 392,50 metros como cota máxima normal de operação do lago (ou elevação máxima do nível que a água do reservatório pode atingir) (Reis, 2003), criando-se um buffer de 100 metros a partir desse ponto (FUPEF, 2007).

A APP do entorno do lago totaliza 13.895,96 hectares (Figura 1), compostos por usos diversificados. Esta área, adquirida e desapropriada, por obrigação legal, pela concessionária de energia elétrica Companhia Hidroelétrica do São Francisco (CHESF), foi estabelecida em conformidade com o licenciamento ambiental da barragem (FUPEF, 2007).

Na APP da Barragem de Sobradinho há o predomínio do uso de culturas diversificadas associadas à vegetação nativa $(37,22 \%)$, bem como o uso da área de vazante $(28,19 \%)$. A Figura 1 ilustra o trecho da APP com predomínio do uso de culturas diversificadas associadas à vegetação nativa, tendência evidenciada em toda a sua extensão (37,22\%), conforme identificado na Tabela 1.

A extensão da APP da Barragem de Sobradinho que corresponde ao uso de culturas diversificadas e sujeitas à variação do nível da água totaliza 65,41\% (FUPEF, 2007). Dadas as características da produção agrícola familiar, cuja base é a diversificação, bem como a utilização das áreas naturalmente fertilizadas pelas cheias periódicas (áreas de várzea), infere-se que a ocupação de ambas as áreas seja dada por agricultores familiares.

\footnotetext{
3 Resolução CONAMA n. 302, de 20/03/2002, art. $3^{\circ}$, item I.
} 


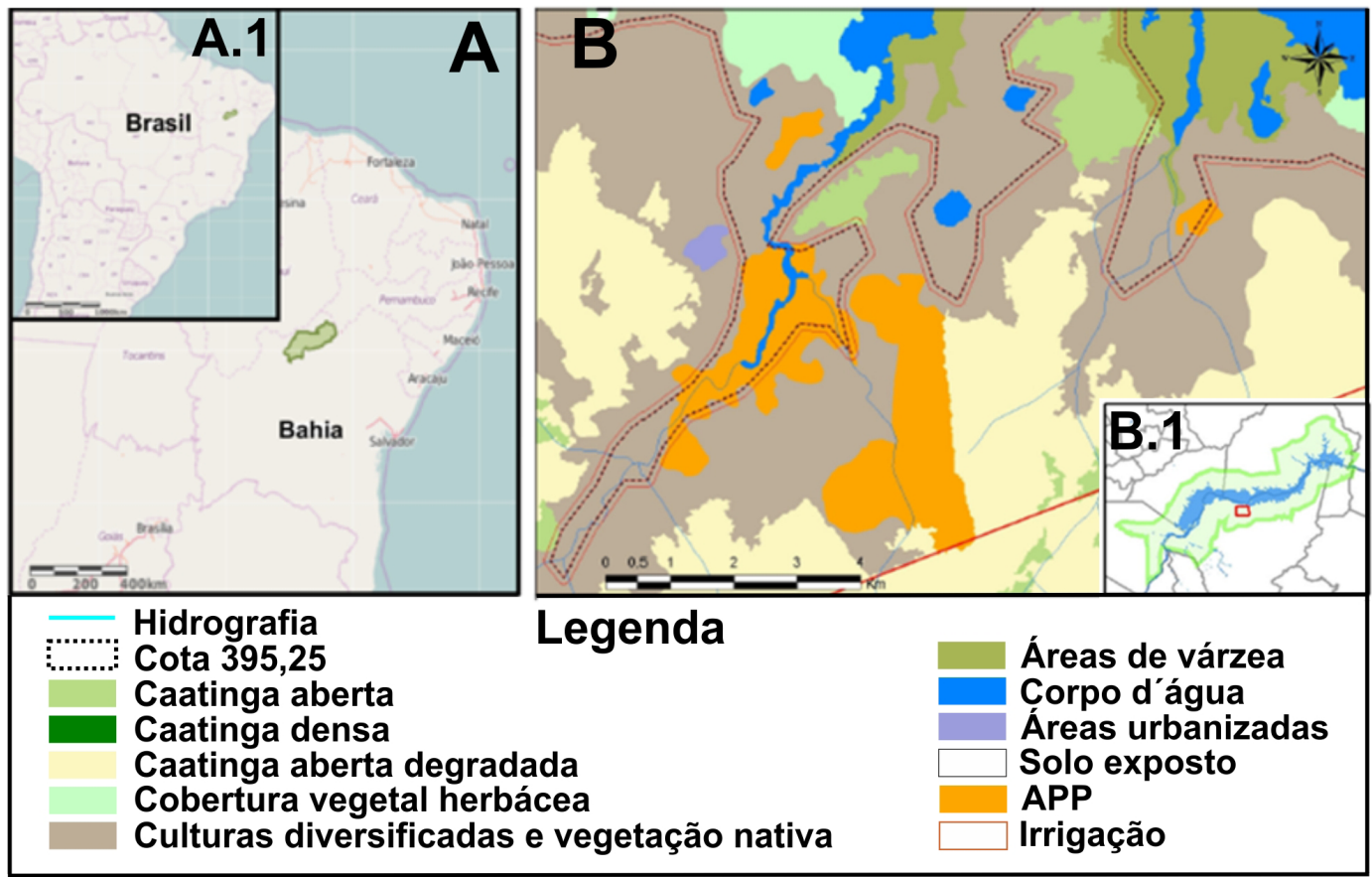

FIGURA 1 - Área de Preservação Permanente (APP) do lago de Sobradinho evidenciada em verde no Estado da Bahia (A) e no Brasil (A1). Detalhe do mapa de uso do solo de área (B) localizada dentro da APP do lago de Sobradinho (B1).

FONTE: Adaptado de ESRI (2016) e FUPEF (2007).

TABELA 1 - Área e respectivo percentual das diferentes classes de uso do solo na APP do lago da barragem de Sobradinho, no Estado da Bahia.

\begin{tabular}{lcc}
\hline Classe de uso do solo & Área (ha) & \% \\
\hline Caatinga densa & 169,87 & 1,22 \\
Caatinga densa degradada & 357,49 & 2,57 \\
Caatinga aberta & 982,08 & 7,07 \\
Caatinga aberta degradada & $1.240,13$ & 8,92 \\
Cobertura vegetal herbácea & 543,26 & 3,91 \\
Vegetação ciliar associada à pequena irrigação & 5,7 & 0,04 \\
Áreas desmatadas & 233,94 & 1,68 \\
Culturas diversificadas associadas com vegetação nativa & $5.171,55$ & $37,22\left(^{*}\right)$ \\
Irrigação & 742,87 & 5,35 \\
Corpo d'água & 460,05 & 3,31 \\
Solo exposto & 9,66 & 0,07 \\
Áreas urbanizadas & 9,07 & 0,07 \\
Nuvens e sombras & 3,55 & 0,03 \\
Irrigação associada a áreas pouco produtivas & 49,32 & 0,35 \\
Áreas sujeitas a variações no nível de água (áreas de várzea) & $3.917,42$ & $28,19\left(^{*}\right)$ \\
TOTAL & $\mathbf{1 3 . 8 9 5 , 9 6}$ & $\mathbf{1 0 0}$ \\
\hline
\end{tabular}

(*) A área utilizada por agricultores familiares equivale a 65,41\% da extensão da APP da barragem de Sobradinho. FONTE: FUPEF (2007). 
Embora a Lei 12.651, de 2012, admita o plantio de culturas temporárias e sazonais de vazante de ciclo curto na faixa de terra que fica exposta no período de vazante dos rios ou lagos pela pequena propriedade ou posse rural familiar, os dados mostram que a área ainda sem exploração significativa, equivalente a $12,2 \%$, encontra-se pressionada por ocupações ${ }^{4}$. Este fato coloca em xeque não somente a capacidade de resiliência deste ecossistema, mas a própria sobrevivência dos agricultores, coadunando com as exigências legais de que o uso dessas áreas somente será permitido se não implicar supressão de novas áreas de vegetação nativa, além da garantia de conservação da qualidade da água, do solo e da proteção da fauna silvestre.

A ausência de um instrumento de comando e controle que assegure o uso e a ocupação dessas áreas com base nos termos exigidos na fase de licenciamento e nas adequações às normas legais, associada às divergências de iniciativas dos diversos atores que atuam neste espaço/território, tem gerado pulverização de esforços no sentido de preservar os recursos naturais. $\mathrm{O}$ fato é que, embora a utilização dessas áreas venha ocorrendo com base no uso e no manejo inadequados dos ativos ambientais e sem o cumprimento das obrigações legais, são tímidas as ações públicas que objetivem disciplinar as atividades já existentes ou mesmo extinguir as que promovem sérios impactos ambientais.

$\mathrm{O}$ descumprimento das exigências legais em imóveis rurais nessa localidade, assim como no país como um todo, é favorecido pelo fato de não existir uma estrutura de monitoramento e de fiscalização eficiente (Irigaray, 2007). Em Santa Catarina, por exemplo, Hodge et al. (1997) ressaltam a incapacidade do órgão ambiental federal e estadual em realizar o monitoramento e a fiscalização ambiental em todos os municípios do Estado. Entre os motivos, estariam o limitado número de pessoal contratado e a necessidade de deslocamento às áreas localizadas distantes da sede, com altos gastos de recursos e de tempo (Hodge et al., 1997).

Nem mesmo as alternativas previstas por Lei para o proprietário que desmatou sua área de RL, como a sua recuperação e a compensação por outra área, vêm sendo adotadas pelos proprietários ou incentivadas pelo Estado de forma consistente (Irigaray, 2007). Dessa forma, as atividades agropecuárias, mais comumente a monocultura e a pecuária extensiva, não vêm encontrando restrições para o avanço sobre as áreas de RL e APP, aumentando o passivo ambiental com a perda desses remanescentes e a sua biodiversidade associada (Irigaray, 2007).

Por outro lado, deve-se notar que as instituições governamentais voltadas à promoção do desenvolvimento agrícola no meio rural também contribuem para este descaso com a legislação que trata da proteção da vegetação nativa. A título de exemplo, cita-se a ausência da incorporação de critérios relacionados à legislação florestal na concessão do crédito e seguro agrícola (ISA \& ICV, 2006). As tentativas de promover um "esverdeamento" do sistema de crédito oficial por meio da iniciativa denominada Protocolo Verde não tiveram êxito (Young, 2005). A implementação de uma eventual política oficial de crédito atrelada aos parâmetros ambientais deve contar com um maior rigor na adoção de critérios ambientais por parte de instituições financeiras privadas, a fim de não comprometê-la (ISA \& ICV, 2006).

A falta de reconhecimento por parte das instituições de crédito de que a eficiência da atividade agrícola depende do uso adequado dos recursos

4 Caatinga densa, catinga aberta e cobertura herbácea. 
ambientais da propriedade rural afeta a sustentabilidade da própria atividade. Este fato pode resultar em prejuízos não somente à biodiversidade ou aos beneficiários do investimento, mas ao próprio sistema de crédito, uma vez que os impactos ambientais causados pela atividade agrícola podem comprometer a capacidade dos produtores em pagar sua dívida (ISA \& ICV, 2006). O cumprimento do Código Florestal também poderia ser beneficiado pela integração das ações entre Instituto Nacional de Colonização e Reforma Agrária (INCRA), IBAMA, Receita Federal e o órgão estadual ambiental (ISA \& ICV, 2006). A esse respeito, cabe destacar o pensamento de autores como Soulé (1991), Milaré (2001) e Gualda (2002), que afirmam que o progresso na atividade de conservação é impedido pela falta de uma política pública para biodiversidade claramente articulada com outras políticas nacionais.

Esta desarticulação compartilha de uma visão que valoriza aspectos puramente econômicos (Song \& Gonigle, 2001) e acredita que o desmatamento é necessário para o crescimento econômico do país (Young, 2004). No entanto, evidências demonstram que a relação positiva entre desmatamento e melhoria das condições de vida da população não é real. Um estudo realizado por Andrade (2003, apud Camphora \& May, 2006) nos estados da região Sul mostrou que municípios com maior índice de desmatamento apresentavam um menor nível de produção e de emprego no setor agrícola comparado à média dos municípios desta região.
Isso pode ser associado à deterioração na provisão de serviços ambientais importantes para o desempenho agrícola; podendo-se citar como exemplo a polinização, controle de erosão do solo, manutenção da qualidade da água, entre outros.

Como um exemplo de instrumento que deu resultados positivos em termos de conservação dos remanescentes florestais, cabe mencionar o SLAPR anteriormente apresentado. Este vem possibilitando a aplicação de penalidades previstas na legislação florestal e o controle dos desmatamentos ilegais por meio do monitoramento da dinâmica de uso e ocupação do solo em imóveis rurais (MMA, 2006).

\section{Discussão}

Como observado, a política ambiental brasileira e seu sistema de gestão ambiental, em que reside a promoção da preservação de remanescentes, seguem, fundamentalmente, os instrumentos de regulação ou de comando e controle. Esta característica pode estar relacionada à economia que estes comportam ao Estado, haja vista que, neste sistema, os custos de manejo dos remanescentes recaem em grande parte ao proprietário (Bowers, 1999). Contudo, mecanismos de proteção ambiental baseados em sanções implicam também maiores chances de insucesso comparados àqueles com maior ênfase em incentivos (Bowers, 1999). Isso está associado ao risco moral ${ }^{5}$, que faz com que, para garantir a implementação da medida legal, as autoridades

\footnotetext{
5 O risco moral ou moral hazard está relacionado à assimetria informacional, em que uma parte de uma relação econômica possui mais informações do que a outra. Um caso típico de risco moral é denominado problema agente-principal. O agente, de maneira geral, tem mais informações sobre suas ações ou intenções do que o principal e a sua conduta ou comportamento não é conhecido. Por ter a sua ação oculta, o agente tende a ser oportunista, especialmente porque o principal não pode monitorar perfeitamente o agente (Benjó, 1999). No caso da implementação da legislação ambiental, as autoridades ambientais (principal) não são capazes de distinguir se a eventual perda de biodiversidade de fragmentos florestais localizados em uma propriedade rural se deu devido a falhas de manejo cometidas pelo proprietário rural (agente) ou devido a fatores ambientais exógenos (Bowers, 1999). Esse risco moral está associado ao fato de os proprietários rurais não terem incentivos para promover a manutenção da biodiversidade dos fragmentos florestais em suas áreas. Os incentivos são os principais instrumentos utilizados para reduzir a assimetria informacional entre o agente-principal.
} 
devam monitorar as atividades nas áreas protegidas (RL, APP e UCs) de forma constante e ininterrupta (Bowers, 1999; ANA et al., 2004), com alto dispêndio de recursos financeiros. O risco moral acontece porque a sanção legal envolve custos de manutenção e até de fiscalização dos remanescentes ao proprietário pelos quais ele não é ressarcido (Lins, 2005). Esta condição tende a fazê-lo negligenciar suas obrigações de manejar adequadamente o remanescente, atribuindo a fatores exógenos a resultante degradação do remanescente (Bowers, 1999). Esta atitude é muito comum entre proprietários rurais no país, sendo retratada por Hodge et al. (1997) em Santa Catarina. Contudo, mecanismos que visam incentivar os proprietários a manter os remanescentes estão sendo incorporados, como no caso das RPPNs e da Cota de Reserva Ambiental, que podem ser comercializadas entre proprietários que possuem percentuais de vegetação que excedem os percentuais legais e aqueles que não atingem a cota obrigatória.

Diante do exposto, é possível concluir que as ações legais voltadas à proteção de remanescentes poderiam se beneficiar da adoção de um maior número de incentivos. Nesse sentido, torna-se relevante mencionar a experiência do Reino Unido e da Austrália com instrumentos econômicos no âmbito da proteção de remanescentes em áreas privadas. Nestes países, além de restrições legais à supressão de vegetação nativa e a isenção de impostos territoriais sobre áreas com remanescentes, verifica-se o estabelecimento de acordos voluntários e por tempo determinado entre proprietários de remanescentes e agência ambiental. Nestes acordos, os proprietários se comprometem a manejar o remanescente de forma a manter o seu valor ecológico e sua integridade em troca de uma compensação financeira (Bowers, 1999). O emprego destes acordos por parte das autoridades ambientais tem o intuito de reduzir a possibilidade de ocorrência do risco moral, uma vez que o pagamento é condicionado à manutenção do valor ecológico do remanescente. Contudo, Bowers (1999) faz uma ressalva: para que esses incentivos sejam realmente eficazes, estes, em tese, devem ser suficientes para compensar os lucros perdidos, os custos do manejo diferenciado para os remanescentes, além de um prêmio pela contribuição à conservação da biodiversidade e manutenção de serviços ambientais, o que pode onerar ainda mais o Estado.

Fica evidente, portanto, que os bens ambientais estão no centro das disputas e dos conflitos entre indivíduo e sociedade. De pronto, seu acesso é restrito e diferenciado, dadas as condições de desigualdade entre os indivíduos na luta pelo bem: monetários; de informação; de poder ou barganha. Seu uso resulta em atividades de exploração, seja para sobrevivência, seja objetivando ganhos econômicos. Deles decorrem externalidades negativas, que são agravadas pela condição de que os recursos naturais são bens livres, sem qualquer compensação por sua utilização e remetidos à condição de recursos de propriedade comum, sob responsabilidade difusa, endossada pela Constituição Federal ${ }^{6}$.

Nessa perspectiva, o Estado tem sido um dos principais atores balizadores no estabelecimento de regras de gestão, uso e ocupação do território e de seus recursos naturais. Contudo, alguns autores, como Camargo (2002) e Gualda (2002), propõem a ruptura com os mecanismos existentes de gestão ambiental baseados na intervenção estatal, recomendando a sua substituição por mecanismos de mercado.

\footnotetext{
${ }^{6} \mathrm{O}$ meio ambiente é bem de uso comum do povo e essencial à qualidade de vida, impondo-se ao poder público e à coletividade o dever de defendê-lo e preservá-lo para as presentes e futuras gerações (Constituição Federal, artigo 225, caput).
} 
Por outro lado, há o reconhecimento de que o mercado não tem a capacidade de garantir a proteção aos bens naturais (Drummond, 2001), sendo, portanto, necessário manter os instrumentos de $\mathrm{C} \& \mathrm{C}$ de forma combinada à adoção de instrumentos econômicos de mercado.

Por fim, é preciso garantir uma visão crítica, tanto em relação às abordagens de conservação ambiental estritamente econômicas quanto àquelas focadas apenas em medidas regulatórias. Para Schenk et al. (2007), estas abordagens unilaterais têm uma sustentabilidade limitada, quando não integradas a uma estratégia de educação com base na comunicação e na cooperação. Resulta que a aceitação e o comprometimento dos proprietários em relação às medidas governamentais de conservação (incluindo os acordos de manejo baseados em pagamentos) estão relacionados, sobretudo, às ações voltadas para a provisão de informação, a fim de que os proprietários compreendam a importância das medidas promovidas, bem como a construção de redes de cooperação entre os atores (Schenk et al., 2007).

\section{Conclusão}

As políticas que sustentam o objetivo de conservação de remanescentes florestais no país encontram-se centradas principalmente em instrumentos de C\&C com base na implementação de RLs, APPs, UCs, eis que estabelecem o Código Florestal, o SNUC, a PNMA e a Lei de Crimes Ambientais. A implementação desses instrumentos enfrenta vários obstáculos para sua efetivação, que emanam, em grande medida, da necessidade de um pesado aparelho administrativo, de policiamento e punição para o controle dos atores que descumprem as normas. A realidade brasileira mostra que a estrutura de monitoramento e fiscalização ainda é ineficiente, sobretudo em relação à implementação de APPs e RLs (Irigaray, 2007), mas abrange igualmente as UCs e as tentativas de implantação de corredores ecológicos. Portanto, diante do exposto, percebe-se que a estratégia adotada para a conservação de remanescentes florestais no país e prevenção de desmatamento encontra-se distante de cumprir com as metas de biodiversidade estabelecidas para os vários biomas.

Considerando os diferentes instrumentos e estratégias existentes no âmbito da gestão ambiental, a eficácia no alcance das metas e objetivos de biodiversidade assumidos pelo Brasil pode ser beneficiada por uma maior incorporação de IEs, de forma a complementar e fortalecer os instrumentos de C\&C já adotados. Neste mérito, reconhece-se que a aplicação dos instrumentos de $\mathrm{C} \& \mathrm{C}$, de forma isolada, é "insuficiente para assegurar os resultados esperados das políticas ambientais" (May et al., 2005, p. 9). Para tanto, os formuladores de políticas devem se esforçar para combinar de forma mais equilibrada os instrumentos de C\&C e de IEs, além daqueles baseados em estratégias de comunicação e cooperação, equalizando o peso dado aos incentivos e sanções. Algumas das alterações mais recentes do Código Florestal visam sanar essa deficiência quando preveem um programa de apoio e incentivo à preservação e à recuperação do meio ambiente que inclui o pagamento ou incentivo a serviços ambientais (Lei 12.727/2012). 


\section{Referências}

Almeida, L. T. de. O debate internacional sobre instrumentos de política ambiental e questões para o Brasil. In: Anais do II Encontro Nacional da Sociedade Brasileira de Economia Ecológica. São Paulo, 1997. Disponível em: <http:// www.ecoeco.org.br/conteudo/publicacoes/encontros/ii_en/ mesa1/3.pdf $>$.

Amaral, W. A. N.; Brito, M. C. W.; Assad, A. L. D.; Manfio, G. P. (s.d.). Politicas públicas em biodiversidade: conservação e uso sustentado no país da megadiversidade. Disponível em: $<$ http://www.hottopos.com/harvard1/politicas_publicas_em_biodiversi.htm>.Acesso em: 11 jul. 2015.

ANA, GEF, PNUMA, OEA - Agência Nacional de Águas, Fundo para o Meio Ambiente Mundial, Programa das Nações Unidas para o Meio Ambiente, Organização dos Estados Americanos. Programa de ações estratégicas para o gerenciamento integrado do Pantanal e Bacia do Alto Paraguai: relatório final. Brasília: TDA, 2004. 316 p.

Antrop, M. Sustainable landscapes: contradiction, fiction or utopia? Landscape and Urban Planning, 75, 187-197, 2006. doi: 10.1016/j.landurbplan.2005.02.014

Ayres, J. M.; Fonseca, G. A. B.; Rylands, A. B.; Queiroz, H. L.; Pinto, L. P.; Masterson, D.; Cavalcanti, R. B. Os corredores ecológicos das florestas tropicais do Brasil. Belém: Sociedade Civil Mamirauá, 2005. 256 p. Disponível em: $<$ http://uc.socioambiental.org/sites/uc.socioambiental. org/files/Corredores\%20Ecológicos_PPG7_1997_0.pdf>. Acesso em: 11 abr. 2015.

Bastos, N. Z. L. Considerações sobre a Lei da Mata Atlântica. Rio de Janeiro, Monografia (Graduação em Direito) - PUC, 2007. Disponível em: <http://www.puc-rio.br/Pibic/ relatorio_resumo2007/relatorios/dir/relatorio_natasha_zadorosny.pdf.>. Acesso em: 11 abr. 2015.

Benjó, I. Fundamentos de economia da regulação. Rio de janeiro: Thex Ed., 1999. 139 p.

Bowers, J. Policy instruments for the conservation of remnant vegetation on private land. Biological Conservation, 87, 327-339, 1999. doi: 10.1016/S0006-3207(98)00074-3

Brasil. Decreto n. 23.793, de 23 de janeiro de 1934. Aprova o Código Florestal. Brasília: DOU de 9/2/1934.
Brasil. Lei n. 4.771, de 15 de setembro de 1965. Institui o Código Florestal. Brasília: DOU de 16/9/1965.

Brasil. Lei n. 6.938, de 31 de agosto de 1981. Institui a Política Nacional de Meio Ambiente. Brasília: DOU de 02/9/1981.

Brasil. Lei n. 9.433, de 8 de janeiro de 1997. Institui a Política Nacional de Recursos Hídricos. Brasília: DOU de $9 / 1 / 1997$.

Brasil. Lei n. 9.605, de 12 de fevereiro de 1998. Institui a Lei de Crimes Ambientais. Brasília: DOU de 13/2/1998a.

Brasil. Constituição da República Federativa do Brasil, de 5 de outubro de 1988. 11. ed. São Paulo, Atlas 1998b.

Brasil. Lei n. 9.985, de 18 de julho de 2000. Institui o Sistema Nacional de Unidades de Conservação. Brasília: DOU de 19/7/2000.

Brasil. Lei n. 11.428, de 22 de dezembro de 2006. Dispõe sobre a utilização e proteção da vegetação nativa do Bioma Mata Atlântica. Brasília: DOU de 26/12/2006.

Brasil. Decreto n. 6.514, de 22 de julho de 2008. Dispõe sobre as infrações e sanções administrativas ao meio ambiente, estabelece o processo administrativo federal para apuração destas infrações, e dá outras providências. Brasília: DOU de 23/7/2008.

Brasil. Lei n. 12.188, de 11 de janeiro de 2010. Institui a Política Nacional de Assistência Técnica e Extensão Rural para a Agricultura Familiar e Reforma Agrária. Brasília: DOU de 12/1/2010.

Brasil. Lei n. 12.651, de 25 de maio de 2012. Institui o Novo Código Florestal. Brasília: DOU de 28/5/2012a.

Brasil. Lei $n$. 12.727, de 17 de outubro de 2012. Altera a Lei 12.651. Brasília: DOU de 18/10/2012b.

Brito, F. Corredores ecológicos: uma estratégia integradora na gestão dos ecossistemas. Florianópolis: Editora da UFSC, 2006. 273 p.

Bursztyn, M. A. A.; Bursztyn, M. Gestão ambiental no Brasil: arcabouço institucional e instrumentos. In: Nascimento, E. P. de; Vianna, J. N. S. Economia, meio ambiente e comunicação. Rio de Janeiro: Garamond, 2006. p. 85- 112. 
Camargo, A. Agenda 21 brasileira, descentralização de políticas e democratização do planejamento. In: Feldmann, F.; Crespo, S.; Drummond, J. A. (Orgs.). Rio +10 Brasil: uma década de transformações. Rio de Janeiro: ISER, Ministério do Meio Ambiente, Fórum Brasileiro de Mudanças Climáticas, 2002.

Camphora, A. L.; May, P. M. A valoração ambiental como ferramenta de gestão em unidades de conservação: há convergência de valores para o bioma Mata Atlântica? Megadiversidade, 2(1/2), 24-38, 2006. Disponível em: <http:// www.ecoeco.org.br/conteudo/publicacoes/encontros/vi_en/ $\operatorname{artigos} / \mathrm{mesa} 1 /$ a_valoracao_ambiental_como_gestao_UCS. pdf $>$.

CONABIO - Comissão Nacional da Biodiversidade. Resolução n. 03, de 21 de dezembro de 2006. Brasília: DOU $13 / 05 / 2002$.

CONABIO - Comissão Nacional da Biodiversidade. Resolução n. 06, de 3 de setembro de 2013. Brasília: DOU.

CONAMA - Conselho Nacional do Meio Ambiente. Resolução n. 302, de 20 de março de 2002. Brasília: DOU $13 / 05 / 2002$.

Drummond, J. A. Conceitos básicos para a análise de conflitos em torno de recursos naturais. In: Bursztyn, M. (Org). A dificil sustentabilidade política energética e conflitos ambientais. Rio de Janeiro: Garamond, 2001.

ESRI - Environmental Systems Research Institute. Disponível em: <http://www.arcgis.com/home/index.html >. Acesso em: 25 mar. 2016.

Fonseca, B. da C. R. V. As principais alterações trazidas pelo novo Código Florestal brasileiro. Rio de Janeiro, Curso (Pós-Graduação Lato Sensu), Escola de Magistratura do Estado do Rio de Janeiro, 2012. Disponível em: <http://www.emerj.tjrj.jus.br/paginas/trabalhos conclusao/2semestre2012/trabalhos_22012/BeatrizCostaReisValladaresFonseca.pdf > . Acesso em: 18 mar. 2015.

Freitas, A. Palestra proferida durante o Segundo Encontro Nacional dos Povos da Floresta. Brasília - DF. 22 de setembro de 2007.

FUPEF - Fundação de Pesquisas Florestais do Paraná. Plano de ação para atendimento das questões socioambientais e econômicas e recuperação de Áreas de Preservação Permanente da região de influência da barragem de Sobradinho. Relatório de andamento das atividades encomendado pela
CODEVASF - Companhia de Desenvolvimento dos Vales do São Francisco e do Parnaíba. Paraná: FUPEF, 2007.

Gualda, R. As etapas das políticas ambientais no Brasil. In: Feldmann, F., Crespo, S.; Drummond, J. A. (Orgs.). Rio +10 Brasil: uma década de transformações. Rio de Janeiro: ISER, Ministério do Meio Ambiente, Fórum Brasileiro de Mudanças Climáticas, 2002.

Harrop, S. R. Traditional agricultural landscapes as protected areas in international law and policy. Agriculture, Ecosystems and Environment, 121, 296-307, 2007. doi: 10.1016/j.agee.2006.12.020

Hodge, S. S.; Queiroz, M. H.; Reis, A. Brazil's national Atlantic Forest policy: a challenge for state-level environmental planning. The case of Santa Catarina, Brazil. Journal of Environmental Planning and Management, 40(3), 335348, 1997. doi: 10.1080/09640569712128

IBD - Instituto Biodinâmico. Diretrizes para o padrão de qualidade orgânica IBD. Botucatu: Instituto Biodinâmico, 2012. Disponível em: $<$ http://ibd.com.br/Media/arquivo_digital/d2bb080d-d94c-484f-a3e3-d803463418b8.pdf>. Acesso em: 14 jan. 2016.

ICMbio - Instituto Chico Mendes de Conservação da Biodiversidade. Perguntas e respostas sobre Reserva Particular do Patrimônio Natural. Brasília: Ministério do Meio Ambiente, 2012. Disponível em: <http://www.icmbio.gov.br/portal/images/stories/comunicacao/downloads/ perguntaserespostasrppn.pdf>. Acesso em: 15 abr. 2015.

Irigaray, C. T. J. H. Compensação de reserva legal: limites à sua implementação. Revista Amazônia Legal de Estudos Sócio-Jurídico-Ambientais, 1(1), 55-68, 2007.

ISA - Instituto Socioambiental; ICV - Instituto Centro de Vida. Sistema de licenciamento ambiental em propriedades rurais do Estado de Mato Grosso: análise de sua implementação. Brasília: MMA, 2006. Disponível em: <http:// www.mma.gov.br/estruturas/168/_publicacao/168_publicacao30012009114021.pdf>. Acesso em: 13 jan. 2015.

Leal, M. S. Gestão ambiental de recursos hídricos por bacias hidrográficas: sugestões para o modelo brasileiro. Rio de Janeiro, Dissertação (Mestrado em Engenharia) UFRJ, 1997.

Lins, A. S. A decisão de preservar: um estudo das reservas particulares do patrimônio natural na região cacaueira (Sul 
da Bahia - Brasil). Ilhéus, Dissertação (Mestrado em Desenvolvimento Regional e Meio ambiente) - UESC, 2005.

Loureiro, W. ICMS Ecológico: incentivo econômico à conservação da biodiversidade (uma experiência exitosa no Brasil). Revista de Administração Municipal, 44(221), 49-60, 1997.

Loureiro, W. ICMS Ecológico: uma experiência brasileira de pagamentos por serviços ambientais. Belo Horizonte: Conservação Internacional; São Paulo: Fundação SOS Mata Atlântica; Curitiba: The Nature Conservancy (TNC), 2008. Disponível em: <http://www.icmsecologico.org.br/ site/images/artigos/a023.pdf>. Acesso em: 12 fev. 2014.

May, P. H.; Amaral, C.; Millikan, B. Ascher, P. (Org.). Instrumentos econômicos para o desenvolvimento sustentável da Amazônia: experiências e visões. 1. ed. Brasília, DF: Ministério do Meio Ambiente, 2005. 123 p. Disponível em: $<$ http://www.mma.gov.br/port/conama/reuniao/dir894/SeminAMA_InstrumEconom.pdf>. Acesso em: 27 fev. 2014.

MDA - Ministério de Desenvolvimento Agrário. Caderno Pronaf Agroecologia. Disponível em: <http://www.mda. gov.br/sitemda/sites/sitemda/files/ceazinepdf/CADERNO_PRONAF_AGROECOLOGIA_FINAL.pdf $>$. Acesso em: 20 jan. 2015.

Medeiros, R. Evolução das tipologias e categorias de áreas protegidas no Brasil. Ambiente e Sociedade, IX(1), 2006. Disponível em: <http://www.scielo.br/pdf/asoc/v9n1/ a03v9n1.pdf $>$.

Medeiros, R.; Garay, I. Singularidades do sistema de áreas protegidas para a conservação e uso da biodiversidade brasileira. In: Becker, B. K.; Garay, I. (Orgs.). Dimensões humanas da biodiversidade: o desafio de novas relações sociedade-natureza no século XXI. Petrópolis: Vozes, 2006. p. 159-184.

Menezes, J. Projeto de transposição do São Francisco: os perigos da transposição. Folha do Meio Ambiente. Brasília: Folha do Meio Ambiente. Setembro/2007.

Milaré, E. Direito do ambiente: doutrina, prática, jurisprudência, glossário. 2. ed. São Paulo: Ed. Revista dos Tribunais, 2001.

MMA - Ministério do Meio Ambiente. Gestão Ambiental Compartilhada: licenciamento ambiental de empreendimentos e atividades com características de impacto local e os critérios para os municípios exercerem a gestão ambiental. Brasília, 2006. 9 p. Disponível em: $<$ http://www. nuredam.com.br/files/documentos_mec/mma/gestao_ambiental_compartilhada_MMA.pdf $>$. Acesso em: abr. 2015.

MMA - Ministério do Meio Ambiente. Metas nacionais de biodiversidade para 2010. Brasília: MMA, 2007. Disponível em: <http://www.mma.gov.br/estruturas/ sbf_chm_rbbio/_arquivos/Metas\%202010.pdf>. Acesso em: 11 jan. 2015.

MMA - Ministério do Meio Ambiente. Levantamento dos usuários de recursos hídricos e da situação dos remanescentes florestais do entorno do Reservatório de Sobradinho. Brasília: MMA, 2010. Disponível em: <http://www.mma. gov.br/estruturas/sbf2008_df/_arquivos/levantamento_fotogrfico_uhe_sobradinho_parte_1_148.pdf $>$. Acesso em: 11 fev. 2016.

Motta, R. S.; Ruitenbeek, J.; Huber, R. Uso de instrumentos econômicos na gestão ambiental da América Latina e Caribe: lições e recomendações. Texto para discussão n. 440. IPEA, 1996. Disponível em: <http://www.ipea.gov.br/portal/ index.php?option $=$ com_content $\&$ view $=$ article $\&$ id $=3629>$. Acesso em: fev. 2015.

Naughton-Treves, L.; Holland, M. B.; Brandon, K. The role of protected areas in conserving biodiversity and sustaining local livelihoods. Annual Review of Environmental Resources, 30, 219-252, 2005. doi: 10.1146/annurev.energy.30.050504.164507

ONU - Organização das Nações Unidas. Convenção sobre Diversidade Biológica. Rio de Janeiro: Conferência das Nações Unidas sobre Meio Ambiente e Desenvolvimento, 1992.

Pereira, J. S.; Tavares, V. E. Instrumentos de gestão ambiental: uma análise para o setor dos recursos hídricos. Análise Econômica, 17(31), 112-140, 1999. Disponível em: $<$ http://seer.ufrgs.br/index.php/AnaliseEconomica/article/ view/10605/6264>.

Potschin, M.; Haines-Young, R. "Rio + 10", sustainability science and landscape ecology. Landscape and Urban Planning, 75(3-4), 162-174, 2006. doi: 10.1016/J.LANDURBPLAN.2005.03.005

Reis, L. B. Geração de energia elétrica: tecnologia, inserção ambiental, planejamento, operação e análise de viabilidade. São Paulo: Ed. Manole, 2003. 
Sambuichi, R. H. R. Fitossociologia e diversidade de espécies arbóreas em cabruca (Mata Atlântica raleada sobre plantação de cacau) na região Sul da Bahia, Brasil. Acta Botânica Brasileira, 16(1), 89-101, 2002. Disponível em: $<$ http://www.scielo.br/scielo.php?script=sci_arttext\&pid $=$ S0102-33062002000100011>.

Sarney Filho, J. Apresentação. In: MMA. Lei da vida: a lei dos crimes ambientais. Brasília: MMA, 2000.

Schenk, A.; Hunziker, M.; Kienast, H. Factors influencing the acceptance of nature conservation measures: a qualitative study in Switzerland. Journal of Environmental Management, 83, 66-79, 2007. doi: 10.1016/J.JENVMAN.2006.01.010

Secretariado da Convenção sobre Diversidade Biológica. Panorama da Biodiversidade Global 2. Brasília: Ministério do Meio Ambiente, Secretaria de Biodiversidade e Florestas (MMA), 2006. 81 p. Disponível em: <https://www.cbd.int/ doc/gbo/gbo2/cbd-gbo2-po.pdf>. Acesso em: 2 abr. 2015.

Song, S. J.; Gonigle, M. M. Science, power and system dynamics: the political economy of conservation biology. Conservation Biology, 15(4), 980-989, 2001.

SOS Mata Atlântica. Programa de incentivo às RPPNs da Mata Atlântica. Disponível em: <https://www.sosma.org.br/ projeto/programa-de-incentivo-rppns-da-mata-atlantica/>. Acesso em: 15 jan. 2016.
Soulé, M. E. Conservation: tactics for a constant crisis. Science, 253(5021), 744-750, 1991. doi: 10.1126/science. 253.5021 .744

Tabarelli, M.; Pinto, L. P.; Silva, J. M. C.; Hirota, M.; Bedê, L. Challenges and opportunities for biodiversity conservation in the Brazilian Atlantic Forest. Conservation Biology, 19(3), 695-700, 2005.

TNC - The Nature Conservancy. El cacao como cultivo y herramienta de conservación en América Latina: frente a las necessidades del agricultor y de la biodiversidad florestal. Arlington: America Verde, 1999.

Viana, V. M. Biologia e manejo de fragmentos florestais naturais. In: Anais do $6^{\circ}$ Congresso Florestal Brasileiro, Campos do Jordão, 1990. p. 113-118.

Wollmann, L. M.; Bastos, L. C. Novo Código Florestal e reserva legal em propriedades rurais do município de Porto Alegre/RS. Ciência Rural, 45(3), 412-417, 2015. doi: 10.1590/0103-8478cr20140432

Young, C. E. F. Desenvolvimento e meio ambiente: uma falsa incompatibilidade. Ciência Hoje, 36(211), 30-34, 2004.

Young, C. E. F. Financial mechanisms for conservation in Brazil. Conservation Biology, 19(3), 756-761, 2005. 